\title{
Use of MTP kit (Mifepristone and Misoprostol combination pack) for 1st trimester MTP (up to 63 days) at GMERS Dharpur, Patan, Gujarat, India
}

\author{
Parul S. Jani*
}

Department of Obstetrics and Gynecology, GMERS Medical College, Dharpur, Patan, Gujarat, India

Received: 15 June 2018

Accepted: 24 July 2018

\section{*Correspondence:}

Dr. Parul S. Jani,

E-mail: paruparelia@yahoo.in

Copyright: () the author(s), publisher and licensee Medip Academy. This is an open-access article distributed under the terms of the Creative Commons Attribution Non-Commercial License, which permits unrestricted non-commercial use, distribution, and reproduction in any medium, provided the original work is properly cited.

\begin{abstract}
Background: MTP has been legalized in India since 1971. MTP pill (Medical abortion) refers for early pregnancy termination (usually before 9 week gestation) performed without any primary surgical interventions. This study was called out to measure its effectiveness and safety as an abortificiant drug.

Methods: This is a prospective study of 57 cases, conducted at OBSTETRIC and GYNECOLOGY Department, GMERS Medical College, Dharpur, Patan (N.G.) from April 2017 to April 2018.

Results: In present study,61.4\% women are of 20-30 years of age. Majority of women are (82.5\%) of $2^{\text {nd }}$ and $3^{\text {rd }}$ para. Complete abortion was found in $91.2 \%$. Incomplete abortion was in $7 \%$. And there was no effect in $1.8 \%$. Major side effects were bleeding (84.2\%), abdominal pain (85.9\%). Misoprostol related side effects are minimal.

Conclusions: The present observational study demonstrates that mifepristone and misoprostol combined therapy is an effective and well tolerated medication in Indian adult women $(\geq 18$ years) requiring medical termination of intrauterine pregnancy (MTP) up to 63 days' gestation.
\end{abstract}

Keywords: Mifepristone and Misoprostol, MTP, MTP pill

\section{INTRODUCTION}

Abortion is the termination of a pregnancy before the fetus has attained viability, i.e. becomes capable of independent extra-uterine life. The term medical abortion refers to early pregnancy termination (usually before 9 weeks' gestation) performed without primary surgical intervention and resulting from the use of abortioninducing medications. When performed as per guidelines with success rate of 95 to $99 .^{1}$

Drug Controller General of India approved the use of Mifepristone (in April 2002) and Misoprostole (in December 2006) for termination of pregnancy up to 49 days gestation period. In December 2008, Mifepristion +
Misoprostol (1 tab of mifepristone $200 \mathrm{mg}$ and $4 \mathrm{tab}$ of misoprostol $200 \mathrm{mcg}$ each). Combipack was approved by the Central Drugs Standard Control Organization, Directorate General of Health Services for the medical termination of intrauterine pregnancy (MTP) for up to 63 days gestation. ${ }^{2}$

Federation of Obstetrics and Gynecological Societies of India (FOGSI) recommends close monitoring of distribution of drugs that are used for medical abortion and that the medical profession and pharmaceutical industry should exercise due diligence in the promotion and usage of drugs that are used for medical abortion. ${ }^{3}$ As per the MTP law of India, abortion pills can only be prescribed by registered medical practitioner. ${ }^{4}$ 
Mifepristone acts by binding to the progesterone receptor, thus inhibiting the effect of progesterone. The sensitivity of myometrium to exogenous prostaglandins is also increased by administration of Mifepristone. Thus, in early pregnancy, administration of Mifepristone results in regular uterine contractility and increased sensitivity of prostaglandins. ${ }^{5}$ Misoprostol is a synthetic prostaglandins E1 analogue and because of its uterotonic and cervicalripening actions, Misoprostol is also widely used for various gynecological and obstetrical purposes, such as cervical ripening and induction of labour, for pretreatment of the cervix prior to surgical termination of pregnancy and, in combination with Mifepristone for medical abortion. ${ }^{6}$ Prostaglandins causes powerful contraction of uterus. ${ }^{7}$

\section{METHODS}

This study was carried out at Obstetric and Gynecology Department, GMERS Medical college, Dharpur, Patan, (N.G.) from April 2017 to April 2018.

\section{Inclusion criteria}

Women who needed termination of pregnancy with live intrauterine pregnancy up to 63 days gestation, confirmed by ultrasound.

\section{Exclusion criteria}

- Pregnant women more than 63 days of gestation

- Previous allergic reaction to the drugs involved

- Severe anemia

- Pre-existing heart disease

- Undiagnosed adenexal mass

- Intrauterine device in place

- Chronic adrenal failure

- Renal or hepatic failure

- Porphyria and Hemorrhagic disorders

- With concurrent anticoagulant therapy

- Long-term corticosteroid therapy.

All the women were explained about the bleeding and some abdominal pain after taking the drug and all the women were explain about the surgical evacuation in case of incomplete abortion or if there is no effect of the drug. All women had timely access to appropriate emergency medical facilities, if arises.

Day 1 Tab. Mefipristone 200mg.orally

Follow up on Day 2 Tab. Misoprost 400mcg orally given and advised to take another $400 \mathrm{mcg}$ after 12 hours at home.

Follow up on day 14- for final confirmation by clinical examination and ultrasonographic scan that a complete termination of pregnancy had occurred.
Efficacy rates were determined as complete abortion rate, incomplete abortion rate or no response rate observed at Day 14. Based on the outcome of the treatment for each patient.

\section{RESULTS}

Table 1 shows majority of women seeking for MTP pill are of 20-35 years of age accounting for $80 \%$ of case study. Whereas $12.3 \%$ of women were between 15-19 years and $7 \%$ were $35-39$ years.

Table 1: Age distribution.

\begin{tabular}{|c|c|c|}
\hline Age of women & No. $(n=57)$ & $\%$ \\
\hline $15-19$ & 07 & 12.3 \\
\hline $20-24$ & 20 & 35.1 \\
\hline $25-29$ & 15 & 26.3 \\
\hline $30-34$ & 11 & 19.3 \\
\hline $35-39$ & 04 & 7 \\
\hline
\end{tabular}

Table 2: Parity.

\begin{tabular}{|lll|}
\hline Parity of women & No. $(\mathbf{n}=57)$ & $\%$ \\
\hline 1 & 07 & 12.3 \\
\hline 2 & 25 & 43.9 \\
\hline 3 & 22 & 38.6 \\
\hline 4 or more & 03 & 5.3 \\
\hline
\end{tabular}

In Table 2, majority of women are $2^{\text {nd }}$ and $3^{\text {rd }}$ para about $82.5 \%$ of case study and about $12.3 \%$ cases are para 1 and $5.35 \%$ are having 4 or more children.

Table 3: Gestational age.

\begin{tabular}{|lll|}
\hline Age of gestation (days) & No. $(n=57)$ & $\%$ \\
\hline $30-39$ & 14 & 24.6 \\
\hline $40-49$ & 23 & 40.1 \\
\hline $50-63$ & 20 & 35.1 \\
\hline
\end{tabular}

According to Table 3, age of gestation at the time of taking pill shows 40-49 days gestation carries $40 \%$ of case study and 50-63 days of gestation carries 35\%. Early hospital visit (30-39days) consist of $24.6 \%$ of case study.

Table 4: Success rate.

\begin{tabular}{|lll|}
\hline Success rate & No. $(n=57)$ & $\%$ \\
\hline Complete abortion & 52 & 91.2 \\
\hline Incomplete abortion & 04 & 7.0 \\
\hline no effect & 01 & 1.8 \\
\hline
\end{tabular}

Table 4 of success rate shows about $91.2 \%$ of cases all completely aborted when followed up on 14th day, confirmed by ultrasound scanning, only $7 \%$ of cases need surgical intervention due to incomplete abortion and only $1.8 \%$ cases have no effect, so surgical evacuation done. 
Table 5: Side effects.

\begin{tabular}{|lll|}
\hline Side effects & No. $(\mathbf{n}=57)$ & $\%$ \\
\hline Bleeding & 48 & 84.2 \\
\hline Abdominal pain & 49 & 85.9 \\
\hline Nausea & 18 & 31.5 \\
\hline Vomiting & 11 & 19.2 \\
\hline Headache & 03 & 5.2 \\
\hline Backache & 11 & 19.2 \\
\hline Anxiety & 04 & 7 \\
\hline Sleeplessness & 02 & 3.5 \\
\hline Loss of appetite & 05 & 8.7 \\
\hline Diarrhoea & O6 & 10.5 \\
\hline
\end{tabular}

According to Table 5, in present study, the main side effect is bleeding $(84.2 \%)$ and pain related effects -Abd. Pain $(85.9 \%)$, backache $(19.2 \%)$, headache $(5.2 \%)$. With naushea $(31.5 \%)$, and vomiting $(19.2 \%) .7 \%$ had anxiety and $3.5 \%$ had sleeplessness may be due abortion related fear and nervousness. Loss of appetite in 8.7 and and diarrhea was in $10.5 \%$ of cases.

\section{DISCUSSION}

In India, MTP act was passed in 1971 to prevent unsafe and illegal abortion with the aim to reducing the maternal mortality and morbidity due to unsafe abortion. ${ }^{4}$ As per the guidelines for medical abortion in India, medical abortion is only offered only to those patients, who are ready for minimum three follow-up visits, can understand the instruction, ready for surgical procedure if failure or excessive bleeding, good family support and easy access to appropriate healthcare facility. ${ }^{8}$

Present study shows majority of woman seeking for MTP pill are of 20-35yr ages accounting for $80 \%$ of case study. Whereas $12.3 \%$ patients were less then 20 years, compare to study by Sarojini et al $3.8 \%$ patients were less than 19 years of age. ${ }^{9}$ Majority of woman are 2 nd and3rd para about $82.5 \%$ of case study about $12.3 \%$ case are para land $5.35 \%$ are having 4 or more children. Where in a study by Sarojini majority of patients were multigravida. ${ }^{9}$ Age of gestation shows 40-49day gestation carries $40 \%$ of case study and 50-63 day of gestation comprise of $35 \%$. Early hospital visit (30-39days) consists of $24.6 \%$ case. Thus, majority of patients having 40-63 days consist of $75 \%$ cases.

In success rate, Present study Suggest about $91.2 \%$ of case all completely aborted when follow up on 14th day, confirm by ultrasound scanning. In a study by Ashok et al, overall success rate was $97.5 \%$ our success rate is comparable to study by Shivastava in 2006 in Nepal. ${ }^{6,10}$ success rate was $92.6 \%$. Kathleen et al, in 2011 performed similar study and found success rate of $80 \% .^{11}$ Similarly Schaff et al reported success rate of $97 \%$ with $200 \mathrm{mg}$ mifepristone followed by 800 microgram misoprostol vaginally. ${ }^{12}$
In present study, only $7 \%$ of case need surgical intervention due to incomplete abortion which is slightly higher than $2-5 \%$ reported by Ashok et al. In a study by Sarojini et al, surgical evacuation required in $90.4 \%$ and $1-2 \%$ required surgical evacuation for heavy bleeding and $2-3 \%$ need surgical evacuation due to incomplete abortion. ${ }^{6,9}$ Schaff et al reported $2.4 \%$ surgical evacuation rate and spitz IM, and Bardin $\mathrm{CW}$ reported $14.65 \%$ surgical evacuation rate respectively. ${ }^{12,13}$

In present study, only $1.8 \%$ case have no effect. which is higher than the $0.6 \%$ rate reported by Ashok et al Schaff et al reported $0.3 \%$ of cases have no effect at all.,12 Ongoing pregnancy rate with a range of $0.8 \%$ to $1.5 \%$ has been reported by Spitz IM et al. ${ }^{13}$

In side effects, endogenous prostaglandins induce uterine contractility and increase sensitivity of prostaglandins and leads to the uterine bleeding and disruption of placental function. ${ }^{5}$ present study Shows excessive bleeding $84.2 \%$, abdominal pain $85.9 \%$, nausea $31.5 \%$, vomiting $19.2 \%$, backache $19.2 \%$, other side effects are very minimal.In a study by Sarojini et al, $69.3 \%$ patients reported bleeding. ${ }^{9}$ Vaginal bleeding and Uterine cramping are expected. ${ }^{10}$ In present study, pain related side effects are about abdominal pain $85.9 \%$, backache $19.2 \%$ and headache $5.2 \%$.where as in study of Schaff et al, the abdominal cramping c was reported $36.9 \%$ $91.8 \% .^{12}$ Pain related side effects like abdominal pain, backache, headache were experienced due to uterine contraction and misoprostol related side effects. ${ }^{14}$

About Naushea and vomiting and diarrhoea, our study reported $31 ; 5 \%$ and $19.2 \%$ and $10.5 \%$ respectively, in the study of Schaff et al, naushea was reported in 44.6 and $91.8 \% .^{12}$ where as in study of El-Refaey et al, its incidence reported was $70 \%, 44 \%$, and $36 \%$ respectively. ${ }^{15}$ These were attributed due to misoprostol. The most frequent side effects reported in some studies are abdominal pain or discomfort $(56 \%)$, nausea $(54 \%)$, tiredness $(50 \%)$ and breast pain $(28 \%) .{ }^{16}$

In present study, Anxiety, sleeplessness, and loss of appetite were experienced by many number of women. This could be due to mental health of women undergoing the abortion.

\section{CONCLUSION}

Medical abortion is effective and safe if carried out under medical supervision. The standard protocol followed by the hospital was oral administration of $200 \mathrm{mg}$ Mifeprostone followed by (24 hours later) oral administration of Misoprostol $800 \mathrm{mcg}$. The success rate of the combination was excellent and was found to be significantly associated with gestational age. Misoprostol related gastrointestinal side effects were minimal. Unwanted pregnancies due to failure of contraception were one of the noticeable reasons which was intervened and counselled properly. 
Funding: No funding sources

Conflict of interest: None declared

Ethical approval: The study was approved by the Institutional Ethics Committee

\section{REFERENCES}

1. Use of RU-486 with Misoprostol for early abortions in India. Guidelines for Medical Officers, WHOCCR in Human Reproduction. All India Institute of Medical Sciences, Ministry of Health and Family Welfare, Government of India and India Council of Medical Research 2003.

2. Handbook on medical methods of abortion. Available at http://www.health.mp.gov.in/mtp/MMA Reference\%20Manual.pdf

3. The Federation of Obstetric and Gynecological Societies of India. Available at http://www.fogsi.org/index.php?option=com_content and view $=$ articleandid $=97$ Itemid $=16$

4. Government of India. The medical termination of pregnancy rules (amendment). 2003. Ministry of Health and Family Welfare. Department of Family Welfare: notifi cation, New Delhi, the13thJune2003.Available

http;//mohfw,nic.in/index

1.php? sublinkid $=3618$ andlevel $=4$ andlid $=26020$ andla $\mathrm{ng}=1$.

5. Cadepond F, Ulman A, Baulieu E. RU486 (mefipristone) Mechanism of action and clinical uses. Annual Rev Med. 1997;48:129-56.

6. Ashok PW, Flet GM and Templeton A. Mefipristone verses vaginaly administered misoprostol for cervical priming before first trimester termination of pregnancy: A ramdemised, controlled study. American Journal og obstetretics and gynecology 2000;183 (4); 998-1002.

7. Van der Veen N, Brouns J, Doornbos J and Van Wijngaarden W. Misoprostol and termination of pregnancy: is there a need for ultrasound screening in a general population to assess the risk for adverse outcome in cases of uterine anomaly. Arch Gynecol Obstet. 2011;283(1):1-5.
8. Refresher course of medial abortion services. Available at www.ipas.org.media/files/Ipas\%20Publications/REFMAINDE09.A SHX.

9. Sarojini TR, Ashakiran BT Bhanu, Radhika. Overthe-counter MTP pills and it's impact on women's health. J Obstet Gynecol India. 2017;67(1):37-41.

10. Shrivastava V. Safety, efficacy and acceptability of medical abortion with mefipristone and misoprostol in Nepalese women. Nepal J Obstet Gynecol. 2007;2 (2):54-8.

11. Kathleen K, Leslie M, Patricia L, Mithcell D. Mifepristone and Misoprostol for early pregnancy failure: a coholr analysis. Am J Obstet Gynecol. 2011;204(5):386.e1-6.

12. Schaff EA, Eisinger SH, Stadalius LS, Franks P, Gore BZ, Poppema S. Low dose mifepristone 200mg and vaginal misoprostol for abortion. Contraception. 1999 Jan 1;59(1):1-6.

13. Spitz IM, Bardin CW, Benton L, Robbins A. Early pregnancy termination with mifepristone and misoprostol in the United States. N Engl J Med. 1998 Apr 30;338(18):1241-7.

14. Kruse B, poppema S, Creinin MD, Paul M. Management of side effects and complications in medical abortion. Am J Obstet Gynecol. 2000;183(2):S65-S75.

15. El-Refaey H Rajasekar D, Abadalia M, Calder L, Templeton A. Induction of abortion with Mifepristone (RU 486) and oral or vaginal Misoprostol. New Engl J Medic. 2008;332:983-8.

16. Urquhart DR, Templeton AA, Shinewi F. The efficacy and tolerance of mifepristone and prostaglandin in termination of pregnancy of less than 63 days gestation; UK multicenter study-final results. Contraception. 1997;55:1-5.

Cite this article as: Jani PS. Use of MTP kit (Mifepristone and Misoprostol combination pack) for 1st trimester MTP (up to 63 days) at GMERS Dharpur, Patan, Gujarat, India. Int J Reprod Contracept Obstet Gynecol 2018;7:3615-8. 